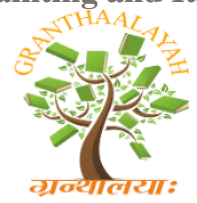

INTERNATIONAL JOURNAL OF RESEARCH GRANTHAALAYAH A knowledge Repository

Science

\title{
EXPERIENTIAL LEARNING: INCLUSIVE ART EDUCATION FOR JOYFUL LEARNING
}

\author{
Prashant Thote ${ }^{1}$, Rajesh Kumar Sen ${ }^{1}$ \\ ${ }^{1}$ Gyanodaya Vidya Mandir, Narsingarh
}

\begin{abstract}
Art integrated learning makes class-room transition joyful, creative and promote appreciation of our rich and cultural heritage. It also promotes art based enquiry, investigation, exploration critical thinking and creativity for class, conceptual understanding of the concepts among the students. It also enhances experiential learning, as it enables students to drive meaning and understanding. Despite the challenging situation facing art education in schools but there are some exemptions. This paper is based on the ethnographic case study of the school to explore art education. In this school art is integrated as natural part of school that has taken holistic approach to education. Art education practices were carried out in creative manner.
\end{abstract}

Keywords: Art Education; Case Study; Holistic and Principle.

Cite This Article: Prashant Thote, and Rajesh Kumar Sen. (2019). "EXPERIENTIAL LEARNING: INCLUSIVE ART EDUCATION FOR JOYFUL LEARNING." International Journal of Research - Granthaalayah, 7(11SE), 111-115. https://doi.org/10.5281/zenodo.3585088.

\section{Introduction}

The students are by nature curious, engage in play with object and respond to music, drama, rhythm and colour. Students from childhood delights in interplay of light, sound, movements, shadow, shape, and colours. Art integrated learning (AIL) is teaching-learning model which is based on learning through art. Art is an expression of ideas created by human imagination, skills and inventions. Art become a medium of teaching-learning, a key element to understand concepts within any subject of curriculum .Students explore creativity while building connections between different concepts through various forms of art. Art experiences both visual (drawing, painting, clay-modeling, pottery, paper craft, mask, puppet-making, heritage craft) and performing arts (music, dance, theater, puppetry etc.,) lead to better understanding and constructions of knowledge and different concepts. Arts have flexibility to accumulate appropriate opportunities for learners who can explore at their individual pace. This resonated with Experiential Learning.

Bengal (2010) state that arts lead to dramatic changes in brain such as strengthening the attention net- work, Brain areas involved in music are also active in processing language, auditory 
Harvey (1989) found that art process relates to cognition, achievement and motivation and selfconcepts in students.

Art is essential in education because it instills in students the habit of mind that last a life time, critical analysis skills, ability to deal with ambiguity to solve problems, perseverance and strive for excellence. The creativity skills among students developed through art carry new ideas; new experience and new challenges not mentioned personal satisfaction. This is the intrinsic value of art which cannot be over estimated.

Art is unique way of knowing and understanding the world. Engagement in quality art education has been said to have a positive effect on overall academic achievement, engagement in learning and development of empathy towards others student's participation in artistic and cultural experiences appears to strengthen their ability to concentrate and engage in personal and social activities, identify perception which later in life increases their confidence and ability to engage in social context .

\section{What is art Integration?}

Art integration is using arts (music, visual art, dance, drama and creative writing) to teach non arts stands (Language, Math's, Science and Social Studies).Art integration is a term applied to an approach to teaching-learning that uses the fine and performing arts as a primary pathway to learning. Art integration diffuses from traditional arts education by inclusion of both an art discipline and traditional subject as part of learning.

\section{Characteristics of Art Integration}

- It is powerful teaching methodology to help the students.

- It is far more than stand-alone activities.

- It nurture higher order thinking skills (HOTS)

- More awareness and efforts combine together to make variety of products.

In the school "Best Out of Waste" activity taken to integrate art and Science

\section{Advantages:}

- Help to generate awareness and building attitude to take activities.

- Controlling amount of waste send into landfills.

- Enables students to give innovative and creative shape.

- Inculcate 5R concepts (Refuse, Reduce, Reuse, Recycle and Recover).

- Helping society of using conservation of ecosystem.

- Developing sense of using ecosystem.

\section{Outcome of learning}

- Optimized used of waste material.

- Minimized harm in waste. 
[Thote et. al., Vol.7 (Iss.11SE): November 2019]

चित्रकला और उसके अंतः अनुशासनिक सम्बन्ध

Painting and Its Interdisciplinary Relation
ISSN- 2350-0530(O), ISSN- 2394-3629(P)

Index Copernicus Value (ICV 2018): 86.20

DOI: 10.5281/zenodo.3585088

- Reduction of cutting tree for paper.

- Development of creative innovation.

- Development of aesthetic appreciation.

- Clean and beautiful surrounding.

- Protection of nature and atmosphere.

- Development of ability to create, develop and present in form of an object.

Activities:

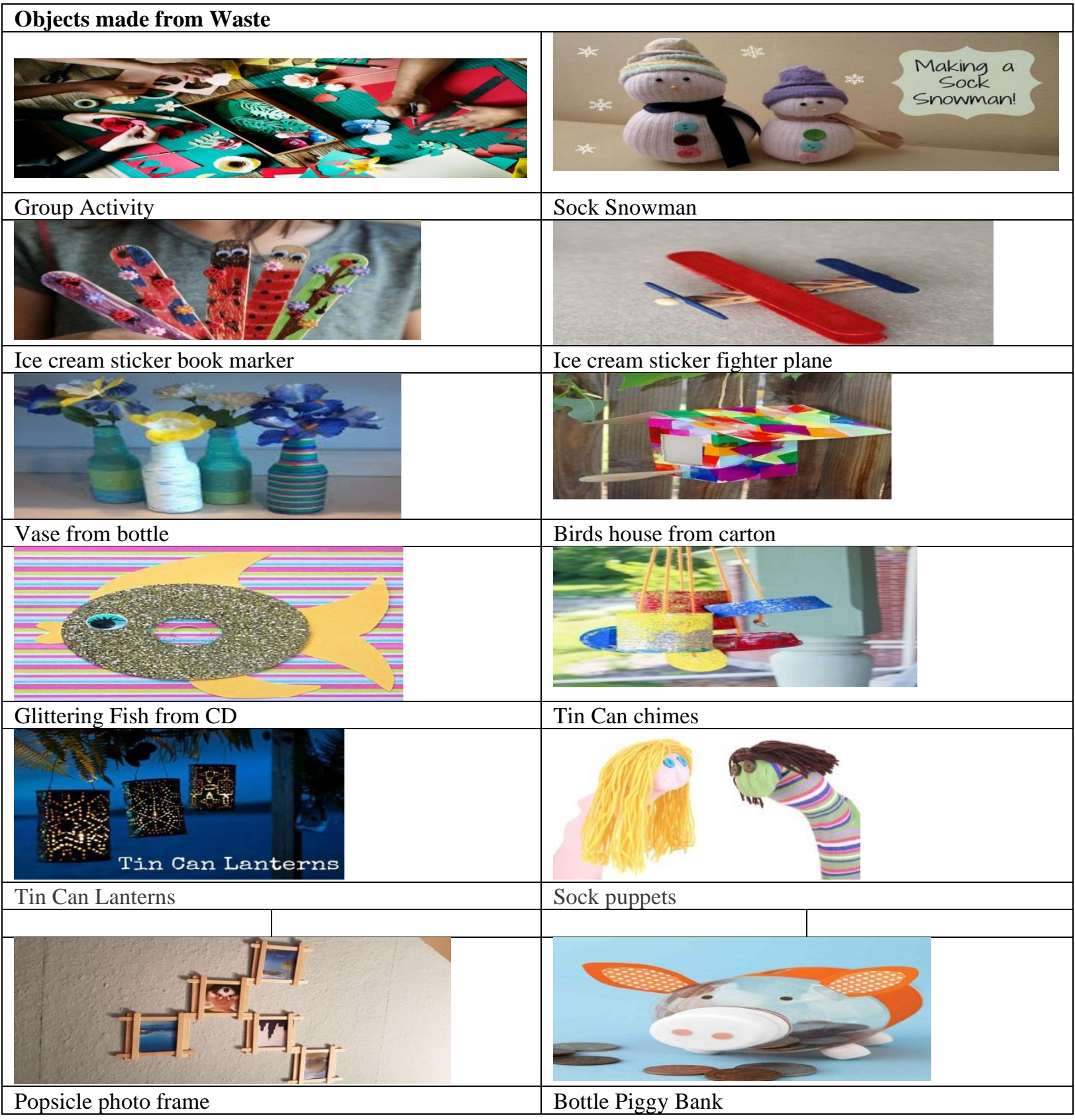




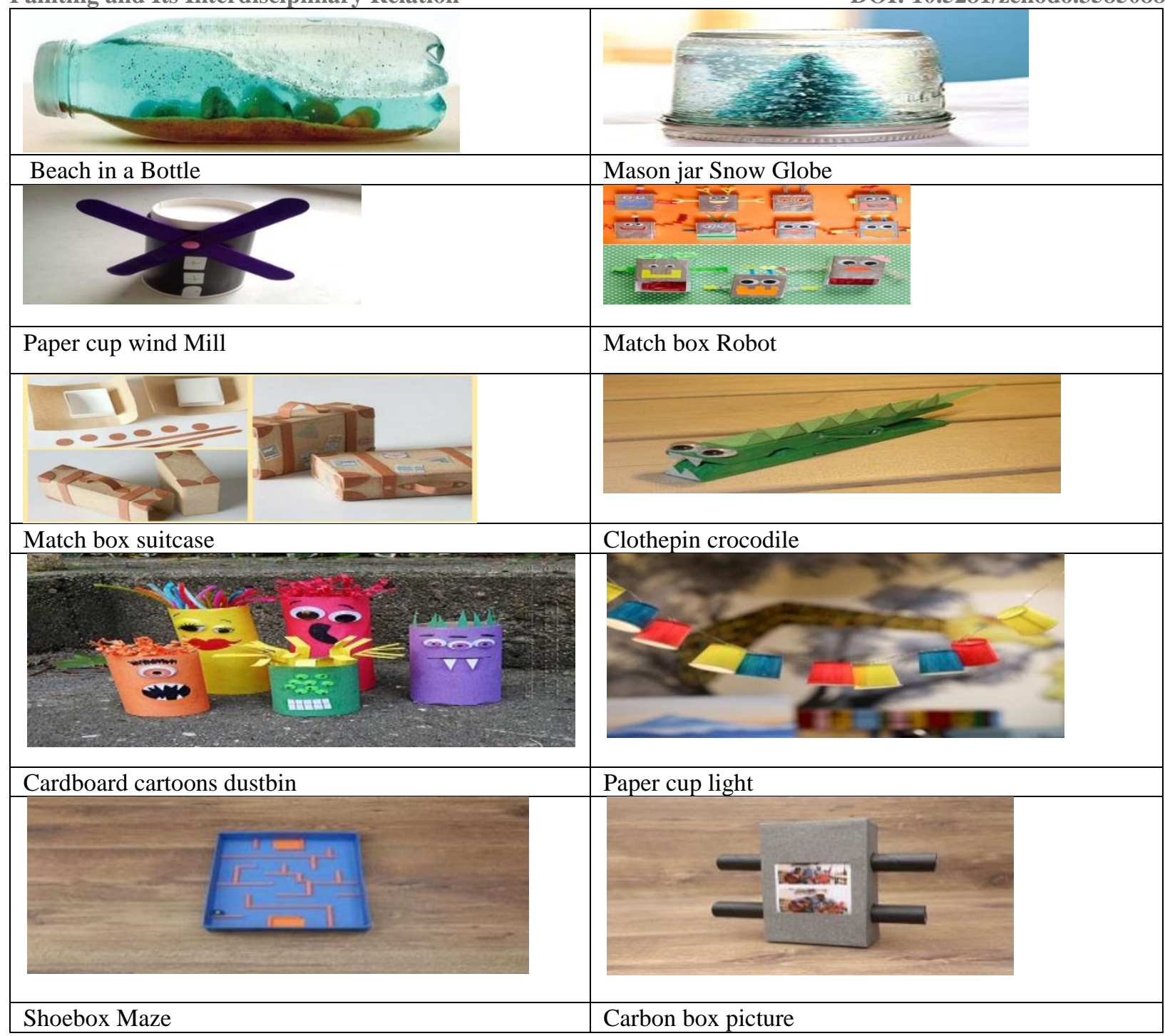

\section{Conclusion}

Gyanodaya Vidya Mandiruse the theme "Best Out of Waste" which is one of such crafts that follow environment friendly principle and at same time create useful and picturesque object out of waste products. In order to create awareness among students on the use of waste material and give them lesson on the reducing waste to save future, Gyanodaya Vidya Mandir regularly conduct the activities based on 5R principles (Refuse, Reduce, Reuse, Recycle and Recover). Little hands and imaginative minds to come together in a creative burst of energy. Mind blowing beyond expectation and fabulous ideas were demonstrated by students. They prepared very creative and innovative models and art items from different waste materials. They use reusable and recyclable materials like newspaper, shoe boxes, bangles, ice cream sticks and much more from these items they created an amazing array of display items which are useful. Everyday objects leaving totally impressed. The value like preservation, recycling, conservation, reduced, recycle, reuse etc. are imbibed on young hearts and minds by demonstrating this noble act of caring our environment. It helped the students to develop their fine motor skills while using different kinds of material and 
also encourages them to use waste material for making decorative and useable items. It was amazing to see how scrap could be transformed into such a useful and beautiful article. The creativity and artistic talent of the children were observed.

\section{References}

[1] Prashant Thote (2019) Experiential Learning: A Corns stone for Education in $21^{\text {st }}$ Century Journal of Research Magma.

[2] Prashant Thote (2019) "Experiential Learning: Model for Teaching Science in Grade Nine Students Achievement". 